Article

\title{
Synthesis and Tribological Behavior of Ultra High Molecular Weight Polyethylene (UHMWPE)-Lignin Composites
}

\author{
Surojit Gupta ${ }^{1, *}$, M. F. Riyad ${ }^{1}$ and Yun $\mathrm{Ji}^{2}$ \\ 1 Department of Mechanical Engineering, University of North Dakota, Grand Forks, ND 58201, USA; \\ riyad.1@buckeyemail.osu.edu \\ 2 Department of Chemical Engineering, University of North Dakota, Grand Forks, ND 58201, USA; \\ yun.ji@engr.und.edu \\ * Correspondence: surojit.gupta@engr.und.edu; Tel.: +1-267-251-4260
}

Academic Editor: Robert J. K. Wood

Received: 9 June 2016; Accepted: 18 August 2016; Published: 31 August 2016

\begin{abstract}
In this paper, we report the synthesis and characterization of ultra-high molecular weight polyethylene (UHMWPE)-lignin composites. During this study four different compositions, namely UHMWPE, UHMWPE-13 wt. \% lignin, UHMWPE-25 wt. \% lignin and UHMWPE-42.5 wt. \% lignin were fabricated by hot pressing. Detailed microstructural studies by scanning electron microscopy (SEM) showed that UHMWPE and UHMWPE-13 wt. \% lignin had a uniform microstructure, whereas UHMWPE- $25 \mathrm{wt}$. \% lignin and UHMWPE-42.5 wt. \% lignin samples were riddled with pores. UHMWPE and UHMWPE-13\% lignin showed comparable flexural strengths of $\sim 32.2 \mathrm{MPa}$ and $\sim 32.4 \mathrm{MPa}$, respectively. However, the flexural strength dropped drastically in UHMWPE-25 wt. \% lignin and UHMWPE-42.5 wt. \% samples to $\sim 13 \mathrm{MPa}$ and $\sim 8 \mathrm{MPa}$, respectively. The tribology of UHMWPE-lignin composites is governed by the tribofilm formation. All the compositions showed similar $\mu_{\text {mean }}$ values and the specific wear rates (WR) decreased gradually as the concentration of lignin in UHMWPE was increased.
\end{abstract}

Keywords: lignin; UHMWPE; mechanical behavior; tribology; particulate additives

\section{Introduction}

Lignocellulosic biomass is targeted as a potentially economical, non-edible feedstock for various industrial applications. The carbohydrate portion of biomass (cellulose facilities) typically makes up two-thirds of the biomass dry matter, comprised of polysaccharides that can be hydrolyzed to sugars and then fermented to products such as ethanol. Lignin, with $15 \%-30 \%$ of biomass dry weight $[1,2]$, is one of the most abundant aromatic compounds on earth and, due to its rigid cross-linked structure and composition, it is the most recalcitrant organic polymer in biomass [3,4]. Currently, most lignin is produced by the pulp and paper industry which is between 50 and 60 million tons per year, of which only $2 \%$ is used commercially and $98 \%$ is burned as a low-cost fuel in the chemical recovery boiler $[5,6]$. A recent report from the U.S. Department of Energy showed that there will be more than one billion tons of biomass feedstock available for biofuel production. As result of the biorefinery developments aimed at replacing fossil feedstocks with lignocellulosic biomass fuels, more lignin could be produced [7]. The chemical structure, molecular weight distribution and degree of crosslinking of lignins are affected by the type of biomass resources and the isolations methods [8]. Therefore, the heterogeneous nature of lignin products with non-uniform and non-standard quality and properties makes it difficult to use as a standard raw material for composites. Cost-effective and reliable methods for the conversion 
and application of lignin other than just simply burning it as a solid fuel are generally technically challenging due to its recalcitrance.

More recently, lignin has been systematically explored by blending it in polymer matrices [9-11]. Various fundamental studies have been done to understand the effect of unmodified lignin on the physical properties of thermoplastic [12-19], thermosets [20], and rubbers [21]. Based on these studies, lignin has been documented to be a promising additive for stabilizing against UV degradation or thermo-oxidation $[9,13,15,16,21]$. The mechanical behavior of these composites is dependent on the interaction between different constituents, for example whether blends can form miscible or can phase separate $[9,18,19,22]$. More particularly, as unmodified lignin contains numerous $\mathrm{OH}$ groups, the lignin molecule is thus relatively polar, and will show comparably better affinity toward polar polymer matrices $[9,18,19,22]$. By chemical treatments, it is also possible to enhance the lignin compatibility with non-polar polymer matrices by derivatizing some or all of the $\mathrm{OH}$ groups, and exposing non-polar groups at the chain end $[9,22,23]$. Clearly, lignin has the potential to be a highly sustainable and versatile additive in engineering plastics.

Curiously, the tribological behavior of lignin-based polymers is not well documented, although it is widely reported in review papers that lignocellulose fibers are a promising additive for tailoring tribological behavior, and compare favorably with conventional fibers $[24,25]$. There is a huge potential that lignin particulates can partially replace some portion of plastics such as ultra-high molecular weight polyethylene (UHMWPE), and can be used for functional components. UHMWPE and its composites are widely studied systems, and they are routinely used for various engineering applications, for example bearing components, gears, guide rails, and in food treatment and medical equipment because of their excellent friction and wear characteristics, corrosion resistance and mechanical properties [26]. The aim of this paper is to understand the effect of unmodified lignin additives on the tribological behavior of engineering plastics, and consequently establish a baseline for future studies for developing triboactive materials by using lignin particulates as additives. More particularly, synthesis, mechanical and tribological behavior of novel lignin-ultra high molecular weight polyethylene (UHMWPE) composites is reported in this paper. It is also well known that the addition of particulates such as kaolin [26], $\mathrm{MoS}_{2}$ [27], and $\mathrm{Ti}_{3} \mathrm{SiC}_{2}$ [28] can tailor the tribological behavior of UHMWPE.

\section{Materials and Methods}

UHMWPE (Product No. 429015, Sigma Aldrich, St. Louis, MO, USA) and lignin (Indulin AT, MeadWestvaco, Richmond, VA, USA) were used for fabricating the composite samples. The UHMWPE-lignin composites were designed by adding $13 \mathrm{wt}$ \% (UHMWPE-13 wt. \% lignin), $25 \mathrm{wt}$. \% (UHMWPE-25 wt. \% lignin) and $42.5 \mathrm{wt}$. \% (UHMWPE-42.5 wt. \% lignin) lignin in UHMWPE matrix, respectively. For comparison, pure UHMWPE samples were also prepared under similar conditions. All the compositions were dry ball milled in a ball mill (8000 M mixer Mill, SPEX SamplePrep, Metuchern, NJ, USA) at 1725 rpm with polymethyl methacrylate (PMMA) balls for 2 min. The mixed powders were then cold pressed in a cylindrical steel die ( $25.4 \mathrm{~mm}$ diameter, MTI Corp., Richmond, CA, USA) by using a Carver Laboratory press (Model 3853, Carver Inc., Wabash, IN, USA) at a uniaxial compaction stress of $\sim 86 \mathrm{MPa}$. All the samples were manufactured hot pressing at $195^{\circ} \mathrm{C}$ at $\sim 86 \mathrm{MPa}$ for $2 \mathrm{~min}$.

The three-point flexural bending test was done for the UHMWPE-Lignin composite samples. The samples were machined into small samples of dimensions $\sim 22 \mathrm{~mm}$ (length), $\sim 2 \mathrm{~mm}$ (thickness), and $\sim 4 \mathrm{~mm}$ (width). For each composition, a set of five samples were tested at a deflection rate of $5 \mathrm{~mm} / \mathrm{min}$ in the mechanical testing system (Shimadzu AG-IS UTM, Shimadzu Scientific Instruments Inc., Columbia, MD, USA). Flexural strength of the composites was calculated by using Equation (1) [29]:

$$
\sigma_{f}=\frac{3 F L}{2 b d^{2}}
$$


where $F$ is the maximum load at the which the sample yielded $(N), L$ is the length of the support span, $b$ is the width of the test beam, and $d$ is the depth or thickness of tested beam.

Samples were mounted on aluminum mounts and coated with $\mathrm{Au} / \mathrm{Pd}$ using a Balzers SCD 030 sputter coater (BAL-TEC RMC, Tucson, AZ, USA). SE (Secondary Electron) and BSE (Back Scattered Electron) images were obtained by using a JEOL JSM-6490LV Scanning Electron Microscope (SEM) (JEOL USA, Inc., Peabody, MA, USA). For microstructure evaluation, UHMWPE and UHMWPE-13\% Lignin samples were finely polished $\left(R_{a}<500 \mathrm{~nm}\right)$ by using diamond suspension (MetaDi ${ }^{\circledR} \mathrm{II}$, Buehler, Lake Bluff, IL, USA). The other compositions were difficult to polish with a fine surface finish, thus machined or fractured surfaces were used for microstructure evaluation for illustrative purposes. The pictures of the tribofilms on the alumina surface were also taken by a digital camera (DSC-HX300, Sony Corporation, Minato, Tokyo, Japan). For the tribology measurements, all the samples were cut into tabs with dimensions of $\sim 4 \mathrm{~mm} \times \sim 4 \mathrm{~mm}$ (cross-section) $\times \sim 3 \mathrm{~mm}$ (thickness). Alumina $(42 \mathrm{~mm}$ diameter and $2 \mathrm{~mm}$ thickness (AL-D-42-2), AdValue Technology, Tucson, AZ, USA) samples were also polished for used as substrates. A surface profilometer (Surfcom 480A, Tokyo Seimitsu Co. Ltd., Tokyo, Japan) was used to measure surface finish. All the samples were polished with $R_{a}<3 \mu \mathrm{m}$. All the tribology studies were then performed by a tab-on-disc tribometer (CSM Instruments SA, Peseux, Switzerland) at $5 \mathrm{~N}(\sim 0.3 \mathrm{MPa}), 50 \mathrm{~cm} / \mathrm{s}$ linear speed, $5000 \mathrm{~m}$ sliding distance, and $\sim 10 \mathrm{~mm}$ track radius. For every composition, three experimental studies were performed. For data analysis, an average of all the friction coefficient $(\mu)$ reading was used to calculate mean response of a single experiment. Thereafter, an average of three mean values was calculated and reported in the text as $\mu_{\text {mean }}$. The mass of the tabs were measured before and after the testing by a weighing scale (XA 83/220/2X, Radwag, Radom, Poland). The specific wear rate (WR) was calculated from Equation (2):

$$
W R=\left(m_{i}-m_{f}\right) /(\rho . N . d)
$$

where $m_{i}$ is the initial mass, $m_{f}$ is the final mass, $\rho$ is density of the composite, $N$ is the applied load, and $d$ is the total distance traversed by the static partner during the tribology testing.

\section{Results and Discussion}

\subsection{Analysis of Microstructure and Mechanical Behavior}

Figure 1 shows the microstructure of the UHMWPE-lignin samples. In general, the pristine UHMWPE sample (Figure 1a) was dense, whereas a small amount of pores was observed in the UHMWPE-13\% lignin sample (Figure 1b); however, as the concentration of lignin was further increased in the UHMWPE matrix, the samples showed a remarkable amount of pores and defects (Figure 1c-f). Figure 2 shows the flexural stress versus displacement plot of lignin-UHMWPE composites. On comparing different stress versus displacement profiles, UHMWPE and UHMWPE-13\% lignin samples showed gradual yielding whereas UHMWPE-25 wt. \% lignin and UHMWPE-42.5 wt. \% lignin showed brittle failure. Figure 3 summarizes the flexural strength of different lignin-UHMWPE compositions. UHMWPE and UHMWPE-13\% lignin showed a comparable flexural strength of $\sim 32.2 \mathrm{MPa}$ and $\sim 32.4 \mathrm{MPa}$, respectively, but the flexural strength dropped drastically in UHMWPE-25 wt. \% lignin and UHMWPE-42.5 wt. \% lignin samples to $~ 13 \mathrm{MPa}$ and $\sim 8 \mathrm{MPa}$, respectively.

Kharade et al. [12] explored lignin powder as a filler in low-density polyethylene (LDPE), high-density polyethylene (HDPE), and polypropylene (PP) up to $30 \mathrm{wt}$. $\%$. In general, the tensile strength of all the polymer composites decreased as compared to HDPE samples. For example, the tensile strength of LDPE reduced from $\sim 10.8 \mathrm{MPa}$ to $\sim 8.9 \mathrm{MPa}$ and $\sim 6.6 \mathrm{MPa}$ after the addition of 10 wt. \% and 30 wt. \% lignin in the LDPE matrix, respectively. Comparatively, the tensile strength of HDPE reduced from $\sim 31.7 \mathrm{MPa}$ to $\sim 19.7$ and $15 \mathrm{MPa}$ after the addition of $10 \mathrm{wt}$. \% and $30 \mathrm{wt}$. \% lignin in the HDPE matrix, respectively. Alexy et al. [13] also observed similar behavior in blending lignin with LDPE and PP blends. For example, the tensile strength of LDPE reduced from 
$\sim 13.5 \mathrm{MPa}$ to $13 \mathrm{MPa}$ and $\sim 5.5 \mathrm{MPa}$ after the addition of $10 \mathrm{wt} . \%$ and $30 \mathrm{wt}$. \% lignin in the LDPE matrix, respectively. Comparably, the present study showed that $13 \mathrm{wt}$. \% lignin can be used in the UHMWPE matrix without affecting its mechanical behavior drastically, but at higher concentrations, the mechanical behavior decreased sharply.
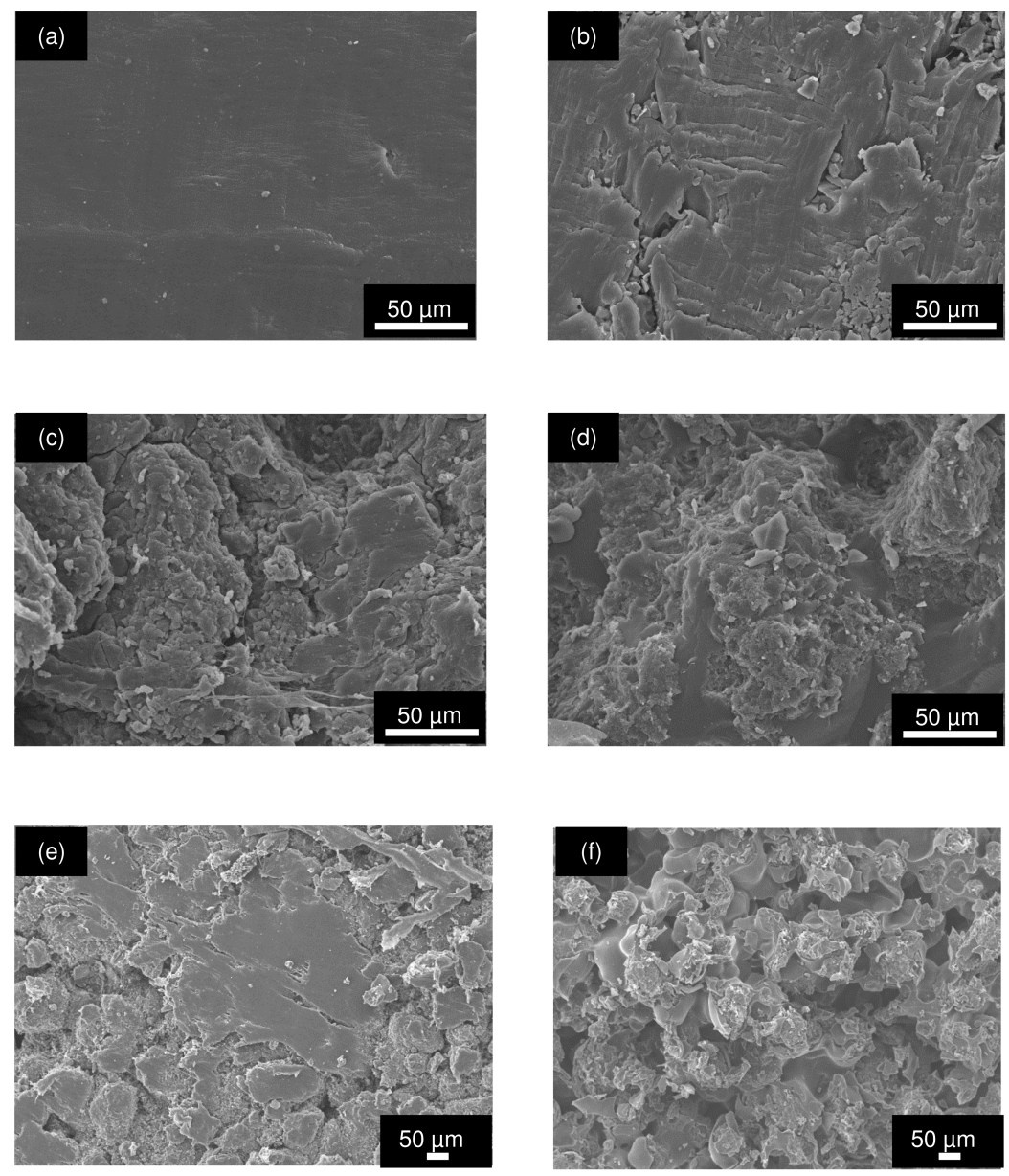

Figure 1. SE SEM micrographs of polished surfaces of (a) UHMWPE; (b) UHMWPE-13\% lignin; (c) UHMWPE-25\% lignin surface machined by a blade and; (d) fractured surface of UHMWPE-25\% lignin; (e) UHMWPE-42.5\% lignin; and (f) fractured surface of UHMWPE-42.5\% lignin.

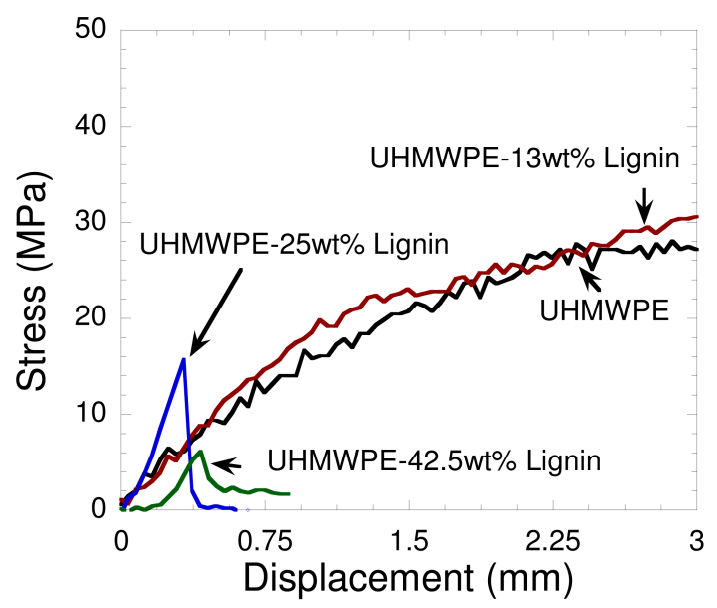

Figure 2. Plot of flexural stress versus displacement of different UHMWPE-lignin composites. 


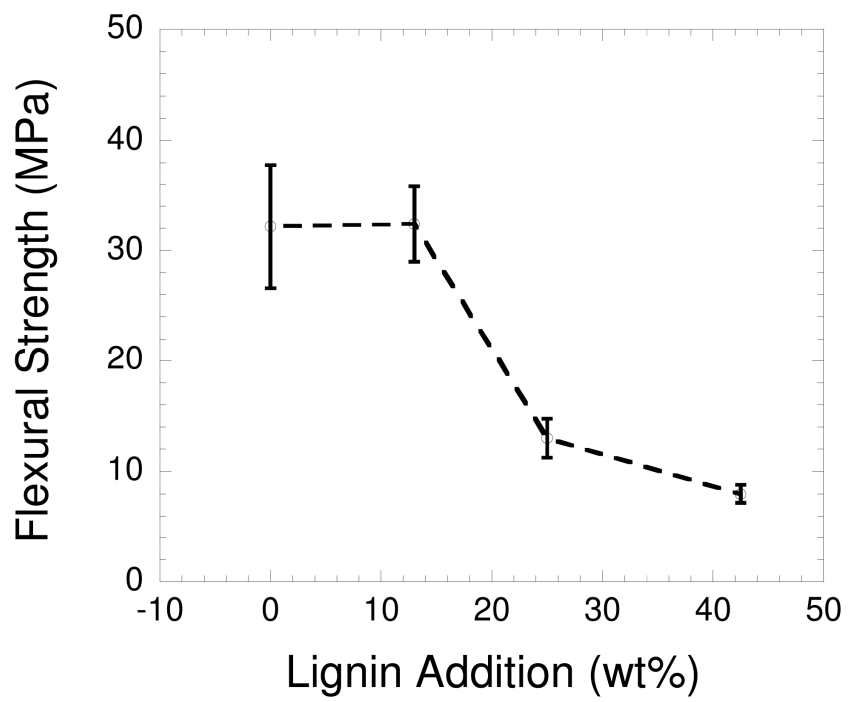

Figure 3. Plot of flexural strength versus lignin addition (wt. \%) in the UHMWPE matrix.

\subsection{Tribological Behavior}

Figure 4 shows the comparison of $\mu$ versus the distance profile of different UHMWPE-lignin compositions. All the compositions showed a similar trend. Initially, the $\mu$ was marginally high (Region I); thereafter, it reached steady state after sliding for $\sim 1000 \mathrm{~m}$ for all the compositions (Region II). Figure 5 compares the $\mu_{\text {mean }}(Y 1$ axis) and WR (Y2 axis) of different compositions. Comparatively, the $\mu_{\text {mean }}$ of all the samples were similar and maintained similar values for all the compositions. However, the WR of UHMWPE increased gradually from $\sim 2.1 \times 10^{-6} \mathrm{~mm}^{3} / \mathrm{N} . \mathrm{m}$ in UHMWPE to $\sim 4.4 \times 10^{-6} \mathrm{~mm}^{3} / \mathrm{N} . \mathrm{m}, \sim 9.5 \times 10^{-6} \mathrm{~mm}^{3} / \mathrm{N} . \mathrm{m}$, and $\sim 2.6 \times 10^{-5} \mathrm{~mm}^{3} / \mathrm{N} \cdot \mathrm{m}$ in UHMWPE-13 wt. \% lignin, UHMWPE-25 wt. \% lignin and UHMWPE-42.5 wt. \% lignin samples, respectively. Table 1 shows a comparison of the tribological behavior of different composite systems. The WR of UHMWPE- $13 \%$ lignin compares favorably as compared to UHMWPE and other tribocouples.

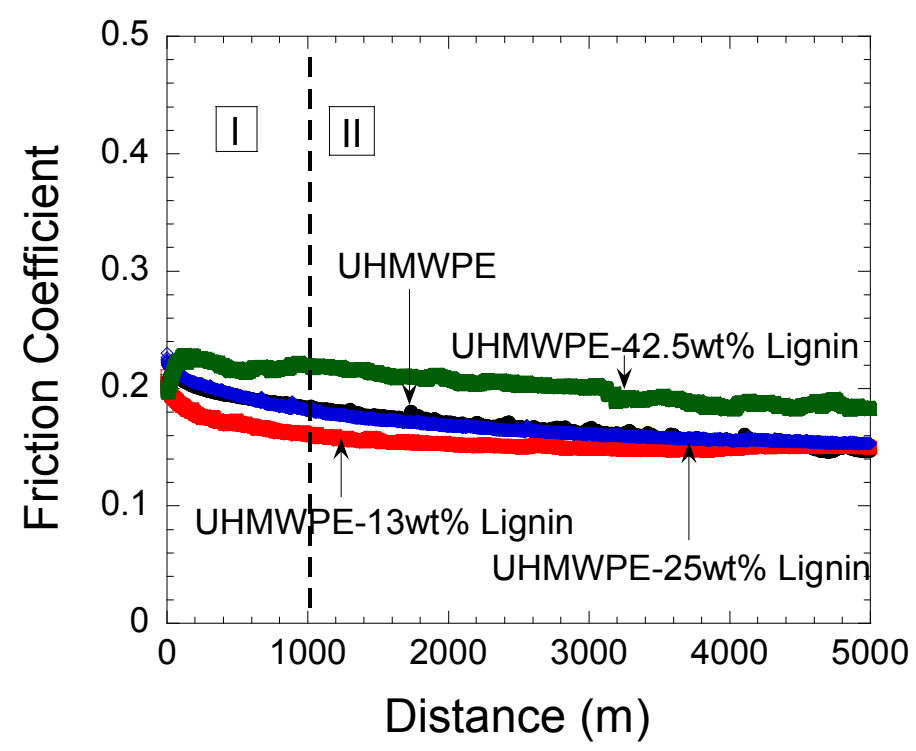

Figure 4. Variation of friction coefficient versus distance of different lignin-UHMWPE composites. 


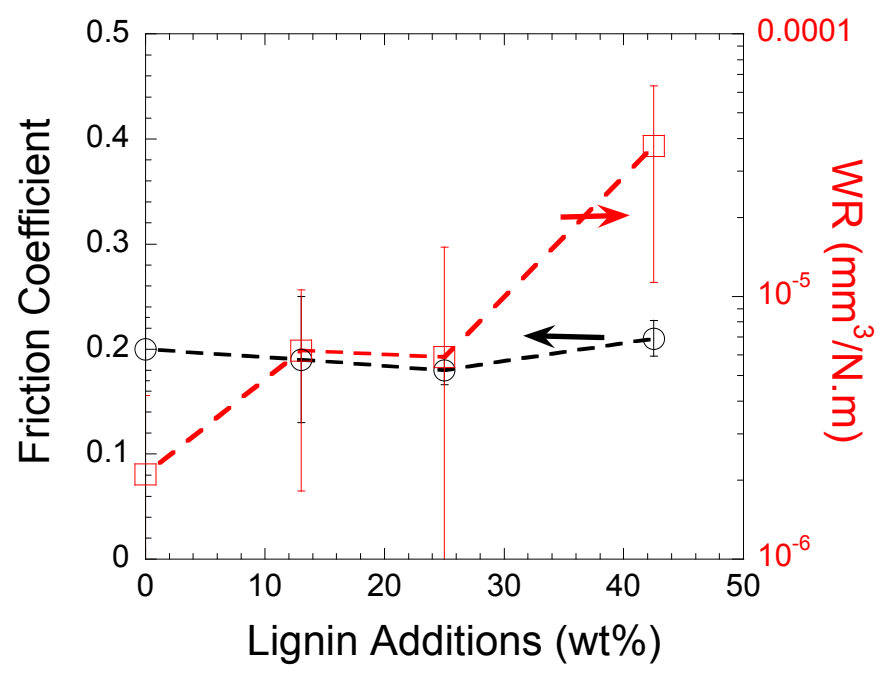

Figure 5. Plot of friction coefficient $(Y 1)$ and $W R(Y 2)$ versus lignin additions (wt. \%).

Table 1. Summary of tribology results of different UHMWPE-based tribosystems.

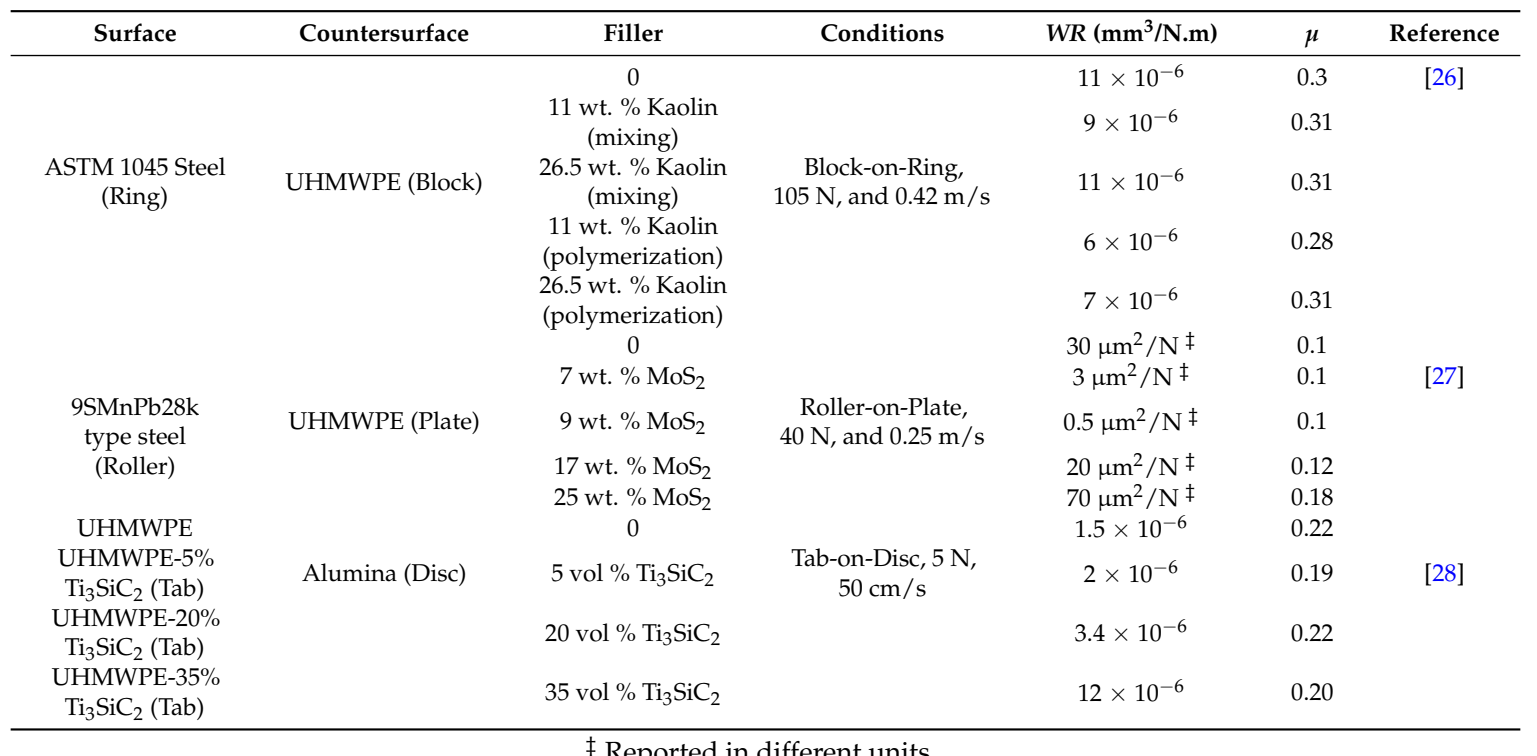

$\ddagger$ Reported in different units.

\subsection{Fundamentals of Tribofilm Formation}

Figure $6 a, b$ show the digital picture of the alumina surface after tribology testing. During testing against UHMWPE, no visible tribofilm was observed on the alumina surface, where as a light brown color tribofilm was observed while testing against UHMWPE-42.5 wt. \%. On further investigation (Figure 6c,d), SE SEM micrographs showed that both the UHMWPE (Figure 6c) and the corresponding alumina surface (Figure 6d), and UHMWPE-42.5 wt. \% (Figure 6e) and the corresponding alumina surface (Figure 6f) are covered with polymer wear debris due to abrasive wear of the UHMWPE and UHMWPE-42.5 wt. \% surfaces, respectively. Clearly, the tribofilm formed between UHMWPE and alumina is thinner and more transparent as compared to the tribofilm between UHMWPE- $42.5 \mathrm{wt}$. \% and the alumina surface which is visible to the naked eye. 

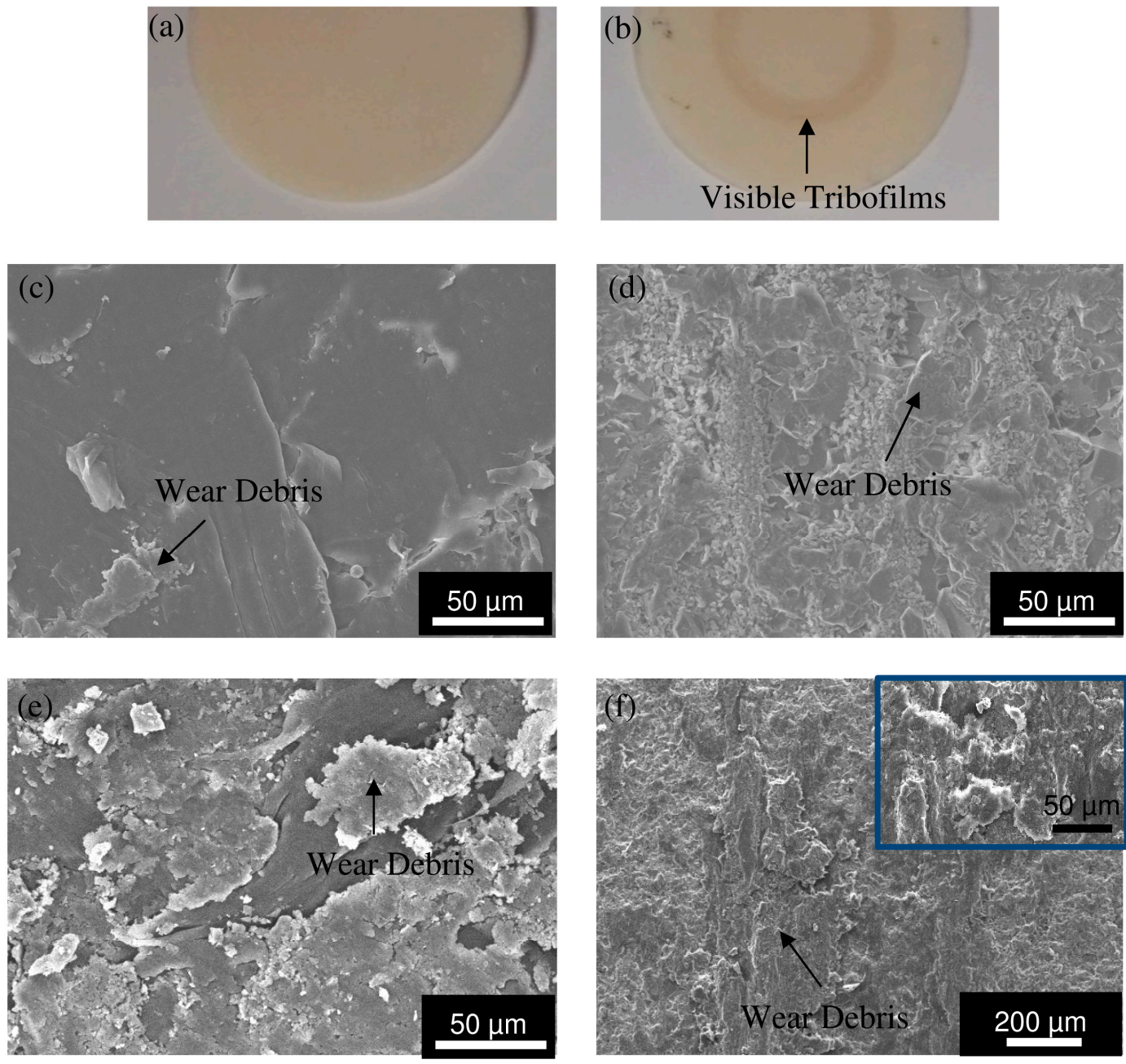

Figure 6. Digital pictures of alumina discs after tribological testing against, (a) UHMWPE and (b) UHMWPE-42.5 wt. \% and SE SEM micrographs of (c) UHMWPE; (d) alumina surface; (e) UHMWPE-42.5 wt. \% and (f) alumina surface (inset shows the morphology of polymer wear debris) after tribological testing.

The tribology of UHMWPE is governed by the formation of tribofilms [26-28,30]. Wang et al. [30] observed the formation of tribofilms composed of reprocessed debris during the steady-state wear of UHMWPE against steel. We saw similar behavior during this study. Bahadur [31] has documented the characteristics of tribofilms during the tribology of polymers. Particulate materials used as the fillers in polymers may either increase or decrease the WR of the tribocouple. For example, $W R$ is increased if the fillers decompose and generate reaction products which enhance bonding between the transfer film and the counterface, whereas the fillers decrease the wear resistance because they generate more discontinuities in the material. UHMWPE-kaolin composites sliding against steel formed very adherent, and thin transfer film showed a better tribological response [26]. Similarly, for example, the addition of $\mathrm{Al}_{2} \mathrm{O}_{3}$ in polyphenylene sulfide (PS) composites lowered the wear resistance of the $\mathrm{Al}_{2} \mathrm{O}_{3}$-PPS composite due the destruction of transfer films [32].

Figure 7 shows a simple schematic of the tribofilm formation between alumina and UHMWPE-lignin composites. Due to the lower mechanical strength of the UHMWPE-lignin composites as compared to UHMWPE (Figure 3), the UHMWPE-lignin samples undergo abrasive wear from alumina surfaces at the tribocontact points (Figure 7a) which results in the formation of brown-colored tribofilms on the alumina surface (Figure 6b) as compared to the transparent tribofilms formed by the UHMWPE sample on the alumina surface (Figure 6a). Consequently, the tribofilms 
formed by lignin-UHMWPE composites against alumina substrates are discontinuous (Figure 6c,d and Figure $7 b$ ), and are not able to prevent further wear. It is recommended that future studies should focus on increasing the interaction between lignin and UHMWPE by engineering the lignin particles using chemical treatments $[9,22]$. In addition, different additives should be explored which can enhance the adherence of tribofilms to substrates for the enhancement of tribological behavior [31,32].

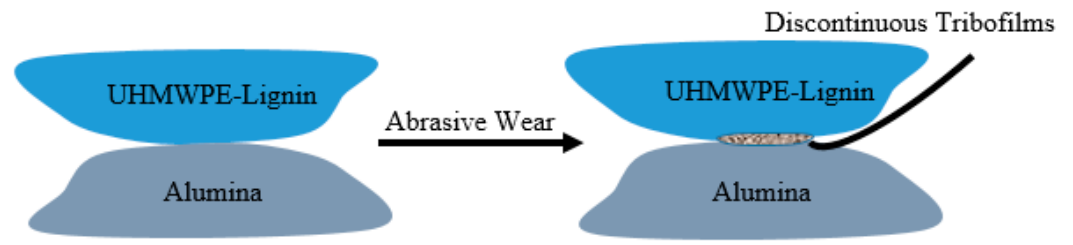

(a)

(b)

Figure 7. Schematics of tribofilm formation in UHMWPE-lignin and alumina tribocouple: (a) tribocontact development; and (b) formation of discontinuous tribofilm formation by abrasive wear of UHMWPE-lignin surface.

\section{Conclusions}

Four different samples, namely UHMWPE, UHMWPE-13 wt. \% lignin, UHMWPE-25 wt. \% lignin and UHMWPE-42.5 wt. \% lignin, were fabricated by hot pressing. Detailed microstructural studies showed UHMWPE and UHMWPE-13 wt. \% lignin had a uniform microstructure, whereas UHMWPE-25 wt. \% lignin and UHMWPE-42.5 wt. \% lignin samples were riddled with pores. Flexural testing showed that the UHMWPE matrix composites can retain their properties until the addition of $13 \mathrm{wt}$. \% lignin, whereas with further additions, the properties of the UHMWPE compositions decreased. For example, UHMWPE and UHMWPE-13\% lignin showed comparable flexural strengths of $\sim 32.2 \mathrm{MPa}$ and $\sim 32.4 \mathrm{MPa}$, respectively, but flexural strength dropped drastically in the UHMWPE-25 wt. \% lignin and UHMWPE-42.5 wt. \% samples to $13 \mathrm{MPa}$ and $8 \mathrm{MPa}$, respectively.

The tribology of UHMWPE-lignin composites is governed by the tribofilm formation. All the compositions showed similar a $\mu$ versus distance profile, and had similar $\mu_{\text {mean }}$ values for all the compositions. However, the WR of UHMWPE increased gradually from $\sim 2.1 \times 10^{-6} \mathrm{~mm}^{3} / \mathrm{N} . \mathrm{m}$ in UHMWPE to $\sim 4.4 \times 10^{-6} \mathrm{~mm}^{3} / \mathrm{N} . \mathrm{m}, \sim 9.5 \times 10^{-6} \mathrm{~mm}^{3} / \mathrm{N} . \mathrm{m}$, and $\sim 2.6 \times 10^{-5} \mathrm{~mm}^{3} / \mathrm{N} . \mathrm{m}$ in UHMWPE-13\% lignin, UHMWPE-25 wt. \% lignin and UHMWPE-42.5 wt. \% lignin samples, respectively. By analyzing the mechanical and tribological performance, it can be concluded that $13 \mathrm{wt}$ \% untreated lignin can be used as an environmentally friendly additive in UHMWPE without compromising the mechanical and tribological behavior.

Acknowledgments: ND NSF EPSCoR is acknowledged for funding. The NDSU Electron Microscopy Center core facility is also acknowledged for the microscopy. This material is also based upon work supported by the National Science Foundation under Grant No. 0619098, and 1229417. Any opinions, findings, and conclusions or recommendations expressed in this material are those of the author(s) and do not necessarily reflect the views of the National Science Foundation.

Author Contributions: S.G. fabricated the composites, performed microstructure evaluation, tribology, and wrote the manuscript; M.F.R. fabricated the composites, performed mechanical testing, analysis, and contributed in writing the manuscript; and Y.J. performed the composite design and analysis.

Conflicts of Interest: The authors declare no conflict of interest.

\section{References}

1. Knauf, M.; Moniruzzaman, M. Lignocellulosic biomass processing: A perspective. Int. Sugar J. 2004, 106, 147-150.

2. Sjöström, E. Wood Chemistry. Fundamentals and Applications; Academic Press: San Diego, CA, USA, 1993. 
3. Gordobil, Q.; Moriana, R.; Zhang, L.; Labidi, J.; Sevastyanova, O. Assessment of technical lignins for uses in biofuels and biomaterials: Structure-related properties, proximate analysis and chemical modification. Ind. Crop. Prod. 2016, 83, 155-165.

4. Hu, T.Q. Chemical Modification, Properties and Usage of Lignin, 1st ed.; Springer: New York, NY, USA, 2002.

5. Christopher, L.P. Integrated Forest Biorefineries, Challenges and Opportunities; RSC Green Chemistry Series; RSC Publishing: London, UK, 2012; p. 32.

6. Song, P.; Cao, Z.; Fu, S.; Fang, Z.; Wu, Q.; Ye, J. Thermal degradation and flame retardancy properties of ABS/lignin: Effects of lignin content and reactive compatibilization. Thermochim. Acta 2011, 518, $59-65$. [CrossRef]

7. Perlack, R.D.; Stokes, B.J. U.S. Billion-Ton Update: Biomass Supply for a Bioenergy and Bioproducts Industry; ORNL/TM-2011/224; Oak Ridge National Laboratory: Oak Ridge, TN, USA, 2011; 227p.

8. Singh, R.; Singh, S.; Trimukhe, K.D.; Pandare, K.V.; Bastawade, K.B.; Gokhale, D.V.; Varma, A.J. Lignin-carbohydrate complexes from sugarcane bagasse: Preparation, purification, and characterization. Carbohydr. Polym. 2005, 62, 57-66. [CrossRef]

9. Duval, A.; Lawoko, M. A review on lignin-based polymeric, micro- and nano-structured materials. React. Funct. Polym. 2014, 85, 78-96. [CrossRef]

10. Thakur, V.K.; Thakur, M.K.; Raghavan, P.; Kessler, M.R. Progress in Green Polymer Composites from Lignin for Multifunctional Applications: A Review. ACS Sustain. Chem. Eng. 2014, 2, 1072-1092. [CrossRef]

11. Doherty, W.O.S.; Mousavioun, P.; Fellows, C.M. Value-adding to cellulosic ethanol: Lignin polymers. Ind. Crop. Prod. 2011, 33, 259-276. [CrossRef]

12. Kharade, A.Y.; Kale, D.D. Lignin-Filled Polyolefins. J. Appl. Polym. Sci. 1999, 72, 1321-1326. [CrossRef]

13. Alexy, P.; Kosıkova, B.; Podstranska, G. The effect of blending lignin with polyethylene and polypropylene on physical properties. Polymer 2000, 41, 4901-4908. [CrossRef]

14. Toriz, G.; Denes, F.; Young, R.A. Lignin-Polypropylene Composites. Part 1: Composites from Unmodified Lignin and Polypropylene. Polym. Compos. 2002, 23, 806-813. [CrossRef]

15. Spiridon, I.; Leluk, K.; Resmerita, A.M.; Darie, R.N. Evaluation of PLA-lignin bioplastics properties before and after accelerated weathering. Compos. Part B 2015, 69, 342-349. [CrossRef]

16. Li, J.; He, Y.; Inoue, Y. Thermal and mechanical properties of biodegradable blends of poly(L-lactic acid) and Lignin. Polym. Int. 2003, 52, 949-955. [CrossRef]

17. Gordobila, O.; Delucis, R.; Egüésa, I.; Labidia, J. Kraft lignin as filler in PLA to improve ductility and thermal properties. Ind. Crop. Prod. 2015, 72, 46-53. [CrossRef]

18. Kadla, J.F.; Kubo, S. Miscibility and Hydrogen Bonding in Blends of Poly(ethylene oxide) and Kraft Lignin. Macromolecules 2003, 36, 7803-7811. [CrossRef]

19. Kubo, S.; Kadla, J.F. Kraft Lignin/Poly(ethylene oxide) Blends: Effect of Lignin Structure on Miscibility and Hydrogen Bonding. J. Appl. Polym. Sci. 2005, 98, 1437-1444. [CrossRef]

20. Thielemans, W.; Can, E.; Morye, S.S.; Wool, R.P. Novel Applications of Lignin in Composite Materials. J. Appl. Polym. Sci. 2002, 83, 323-331. [CrossRef]

21. Kosıkova, B.; Gregorova, A.; Osvald, A.; Krajcovicova, J. Role of Lignin Filler in Stabilization of Natural Rubber-Based Composites. J. Appl. Polym. Sci. 2007, 103, 1226-1231. [CrossRef]

22. Thielemans, W.; Wool, R.P. Lignin Esters for Use in Unsaturated Thermosets: Lignin Modification and Solubility Modeling. Biomacromolecules 2005, 6, 1895-1905. [CrossRef] [PubMed]

23. Sailaja, R.R.N.; Deepthi, M.V. Mechanical and thermal properties of compatibilized composites of polyethylene and esterified lignin. Mater. Des. 2010, 31, 4369-4379. [CrossRef]

24. Nirmal, U.; Hashim, J.; Ahmad, M.M.H.M. A review on tribological performance of natural fibre polymeric composites. Tribol. Int. 2015, 83, 77-104. [CrossRef]

25. Omrani, E.; Menezes, P.L.; Rohatgi, P.K. State of the art on tribological behavior of polymer matrix composites reinforced with natural fibers in the green materials world. Eng. Sci. Technol. 2016, 19, 717-736. [CrossRef]

26. Guofang, G.; Huayong, Y.; Xin, F. Tribological properties of kaolin filled UHMWPE composites in unlubricated sliding. Wear 2004, 256, 88-94. [CrossRef]

27. Pettarin, V.; Churruca, M.J.; Felhos, D.; Karger-Kocsis, J.; Frontini, P.M. Changes in tribological performance of high molecular weight high density polyethylene induced by the addition of molybdenum disulphide particles. Wear 2010, 269, 31-45. [CrossRef] 
28. Gupta, S.; Riyad, M.F. Synthesis and tribological behavior of novel UHMWPE-Ti ${ }_{3} \mathrm{SiC}_{2}$ composites. Polym Compos. 2016. [CrossRef]

29. Meyers, M.A.; Chawla, K.K. Mechanical Behavior of Materials; Prentice-Hall: Upper Saddle River, NJ, USA, 1999.

30. Wang, Y.Q.; Li, J. Sliding wear behavior and mechanism of ultra-high molecular weight polyethylene. Mater. Sci. Eng. 1999, A266, 155-160. [CrossRef]

31. Bahadur, S. The development of transfer layers and their role in polymer tribology. Wear 2000, 245, 92-99. [CrossRef]

32. Yu, L.; Bahadur, S. An investigation of the friction and wear behaviors of ceramic particle filled polyphenylene sulfide composites. Wear 1998, 214, 54-63. [CrossRef] 